\title{
Explaining preferences for home surroundings and locations
}

This article is based on a survey carried out in Denmark that asked a random sample of the population about their preferences for home surroundings and locations. It shows that the characteristics of social surroundings are very important and can be divided into three independent dimensions: avoiding social nuisances, preferring social homogeneity and living close to one's social network and place of origin. The study shows that most people have many detailed preferences, whereas some have very few. This confirms an earlier theory that some people are very connected to certain places with given characteristics and thus do not have priorities regarding home surround- ings and locations. For others, mostly young people and singles, home is just a place to sleep and relax, whereas life is lived elsewhere. For this group, there are only preferences for location and there are few specific preferences for surroundings.

Keywords: residential preferences, surroundings, location, Denmark 


\section{Introduction}

This article reports the results of a Danish study of preferences for home surroundings and locations. The data were obtained from a survey of a random sample of Danes. The article answers the following questions:

- What qualities in home surroundings and locations are most important?

- How can variation in the preferences for these qualities be explained?

- How do preferences develop in different stages of the lifecycle?

- What are the differences among people with different preferences for living in cities or in the countryside?

Little research has been carried out regarding housing preferences and how and why they vary between different groups and geographical areas. One of the reasons is that it is difficult to directly determine housing preferences because of housing-market problems and because people often lack sufficient resources, with the result that they are unable to realise their preferences and live in their preferred type of home and surroundings. There are also some methodological issues connected with research on housing preferences, whether studying where people want to live or their actual housing situation. However, much information has also been obtained from studies on housing demand, on reasons for staying or moving to a home, on place attachment and on housing satisfaction.

The first part of the article clarifies what can be concluded from studies of what people find important concerning home surroundings and locations; however, the results of the studies offer a somewhat confusing picture. Four dimensions are identified a) the physical environment, b) the social environment, c) access to local public and private service facilities and d) location and transport in a broader context. Moreover, it has been shown that preferences vary greatly between people and that this variation primarily depends on differences in family situation and stage of life, income and other resources, and culture and lifestyle.

One major inspiration for this study was the theory proposed by Thorklid Ærø (2002), who asserted that people have different cultural points of reference that determine the degree to which they have strong or weak opinions concerning their home surroundings and locations. Among other things, he highlights the fact that some people may be strongly attached to certain places with given surroundings, but these do not constitute preferences. For other people, the home is just a place to sleep and relax, and they are not particularly concerned about the surroundings. This study appears to confirm Ærø’s theory.

\section{Earlier studies on the importance of home surroundings and locations}

What people find important for the home and its environment may be determined from very different types of research. In addition to specific studies of residential preferences, this may be derived from studies of how people use their homes and feel attached to them. This may be determined through research on causes of "place attachment" and also from studies of satisfaction or dissatisfaction with housing and residential areas.

\subsection{Specific studies of housing preferences}

Specific studies of residential preferences may be based on either stated or revealed preferences, which are the actual choices of surroundings and location (Timmermans et al., 1994; Floor \& Van Kempen, 1997; Coolen \& Hoekstra, 2001). Stated preferences are determined by directly asking people how they would prefer to live and why. Revealed preferences are found by examining how people actually live, and may apply to recent moves or all households. Both methods involve methodological problems. With stated preferences, people do not necessarily take into account the possibilities for realising them. This may mean that there could be significant variations between responses from households that should have the same preferences because some have a realistic picture of their opportunities on the housing market (and include this in their statements), whereas others do not and therefore have preferences that are not realistic. Another common problem is that housing preferences usually consider many different aspects of the home separately. In the real world, people looking for houses consider various combinations of residential properties. Various methods have been developed to handle this complexity (Coolen \& Hoekstra, 2001).

A distinction has been made among the following (Floor \& Van Kempen, 1997):

- Absolute preferences for the home, its surroundings and location that are essential conditions for accepting a home;

- Trade-off preferences that may be sacrificed if other benefits can be achieved; and

- Relative preferences that are important but do not entail rejecting the home if unmet.

The problem with the revealed preferences method is that the actual housing situation does not necessarily reflect the underlying preferences. This is because the real opportunities on the housing market and the individual's economic resources play a role. Even when trying to identify economically conditioned preferences, the actual situation may give a false impression 
because market regulations and imbalances may make it impossible to obtain optimal housing (Skifter Andersen \& Bonke, 1980; Timmermans et al., 1994). In addition, different circumstances impeding mobility may result in many families, despite significant changes in housing needs, remaining in homes that over time increasingly differ from their preferences (Skifter Andersen \& Bonke, 1980).

One can talk about "average" preferences only to some extent, but these averages may differ greatly depending on where they are studied, and may also vary between different countries and types of urban areas. Tom Kauko (2006) showed that stated preferences for environment and location differed between Finland and the Netherlands, between central cities and suburbs, and between multifamily and single-family houses. In Finnish multifamily housing, location in relation to work and service had the highest priorities, followed by local services, physical environment and local social conditions. In single-family houses in Helsinki, social conditions were most important, followed by location, physical environment and local services. In Dutch suburbs, physical environment ranked highest, followed by services, location and social factors. In Han Floor and Ronald Van Kempen's study (1997) of stated preferences for home features in the Dutch cities of Rotterdam and Tilburg, home size was often cited as the most important characteristic, followed by housing type, housing costs, presence of a yard, location and local facilities. Preferences for two out of three properties were regarded as absolute; that is, they could not be unmet. This mostly concerned housing size and housing costs, but sometimes also type of building and social composition of the local area. Approximately $20 \%$ of the characteristics were considered trade-off preferences. Most often, environment preferences could be disregarded in favour of lower housing costs or a preferred house type.

Ærø $(2002,2006)$ conducted a comprehensive survey of household moves in the Danish city of Aarhus. He distinguished between home characteristics, tenure, house properties and location, and the social composition of the local area. General features of the home scored highest, followed by surroundings and location. Regarding preferences for location and surroundings, proximity to green areas scored highest, followed by proximity to work, avoidance of traffic and noise, proximity to public transport, proximity to the city centre, reputation and social status of the area, appearance of streets, buildings and squares, private services in the neighbourhood, conditions for children, community spirit, public institutions, sports and leisure facilities, and cultural activities. The study showed some general differences between those that moved to various kinds of housing concerning preferences for neighbourhood characteristics. Owners were more concerned about neighbourhood conditions than renters. Finally, there were preferences concerning the social composition of the neighbourhood residents. The priorities were: a) a high degree of privacy and peace, $b$ ) living among people with similar views on how to behave, c) living close to friends, d) living near others with the same language and cultural backgrounds, e) living near family, f) living near other families with children, g) living near peers, h) living among people with the same taste, i) living near people with the same type of work or education and $\mathrm{j}$ ) living near people with similar hobbies.

\subsection{Neighbourhood satisfaction studies}

The importance of various characteristics of home surroundings and locations has also been examined in the literature on neighbourhood satisfaction. These characteristics have been classified in various ways. The elements in four different studies are classified into five components, as shown in Table 1.

The physical environment component is characterised by Ronald John Johnston (1973) as the "impersonal environment", mainly composed of the physical attributes of the neighbourhood. His study showed that neighbourhood preferences are based on three underlying evaluative dimensions, which are invariant with area of residency in the city. Victoria Basolo and Denise Strong (2002) divided the determinants of neighbourhood satisfaction into individual characteristics of residents and four types of neighbourhood characteristics. One of these was called "physical environmental conditions". In addition, Alison Parkes et al. (2002) organised their variables into six different types, one of which was called "environmental features", measured by asking about the general appearance of the area, leisure facilities and noise.

Location and services were measured by Johnston (1973) in terms of the location attributes of the neighbourhood in relation to the city and its services. Basolo and Strong (2002) called this component "local services/facilities". Parkes et al. (2002) focused on the quality of neighbourhood facilities such as schools, public transport, street lighting and so on, and on access to neighbourhood facilities such as supermarkets, post offices and corner shops. George Galster et al. (2002) conducted a principal component analysis of indicators of neighbourhood quality in six American cities and identified six factors that explained two-thirds of the total variance. One of these was the extent of business and employment in the neighbourhood.

Johnston used a term called the "interpersonal environment", which was mainly composed of the social attributes of the neighbourhood, and Basolo and Strong (2002) referred to the "socio-cultural environment". This could also be called the "social environment". A study by Parkes et al. (2002) split this 
Table 1: Classification of elements in neighbourhood satisfaction.

\begin{tabular}{|c|c|c|c|c|c|}
\hline Study & $\begin{array}{l}\text { Physical } \\
\text { environment }\end{array}$ & $\begin{array}{l}\text { Location and } \\
\text { services }\end{array}$ & $\begin{array}{l}\text { Social } \\
\text { environment }\end{array}$ & Housing & $\begin{array}{l}\text { Reputation/ } \\
\text { status }\end{array}$ \\
\hline Johnston (1973) & "Impersonal environment" & Location attributes & "Interpersonal environment" & & \\
\hline $\begin{array}{l}\text { Basolo \& Strong } \\
\text { (2002) }\end{array}$ & $\begin{array}{l}\text { Physical environmental } \\
\text { conditions }\end{array}$ & $\begin{array}{l}\text { Location characteristics and } \\
\text { services/facilities }\end{array}$ & Sociocultural environment & & \\
\hline Galster et al. (2002) & & Business and employment & $\begin{array}{l}\text { Social disadvantage } \\
\text { Crime rates }\end{array}$ & $\begin{array}{l}\text { Housing and } \\
\text { tenure type } \\
\text { Housing vacancy }\end{array}$ & Prestige \\
\hline Parkes et al. (2002) & Environmental features & $\begin{array}{l}\text { Quality of neighbourhood facilities } \\
\text { Access to neighbourhood facilities }\end{array}$ & $\begin{array}{l}\text { Positive social features } \\
\text { Negative social features }\end{array}$ & Housing satisfaction & \\
\hline
\end{tabular}

component into "positive social features" (friendly neighbours, community spirit) and "negative social features" (crime and safety, bad neighbours). The study by Galster et al. (2002) used "social disadvantage" (female head of household rate, teen birth rates, welfare usage and share of black people), crime (violent crime rates) and "prestige" (share of college degrees, share in managerial, professional and technical occupations, and median home values).

The character of the local housing market in the neighbourhood was shown to be important in the study by Galster et al. (2002). They focused on housing and tenure type (share of single-family homes and owner-occupancy) on housing vacancy (residential vacancy rates and units lacking minimal plumbing) and on housing satisfaction. Parkes et al. (2002) also showed a connection between housing and neighbourhood satisfaction. Many studies have found that fear of crime or lack of safety are very important for neighbourhood satisfaction, in which a high incidence of crime can considerably reduce the usually high neighbourhood satisfaction among residents without plans to move (Skifter Andersen, 2008). There is not always a direct connection between actual crime rates and the perception of local crime among residents (Basolo \& Strong, 2002). Perceived crime is found to be more important to satisfaction than actual occurrence of crime. As stated by Ærø (2006) and Teresa Costa Pinho (2000), the feeling of safety is connected not only to observed crime but also to conflicts between residents or groups of residents. These conflicts can sometimes be based on experiences with other residents not acting in accordance with what is felt to be usual norms and behaviour. This is an argument for claiming that a socially and ethnically heterogeneous neighbourhood has a higher probability of neighbourhood dissatisfaction.

A study by Parkes et al. (2002) found that the most important factor explaining neighbourhood satisfaction, in addition to housing satisfaction, was physical condition ("general appearance of the neighbourhood"). The other important factors were noise, friendliness of neighbours, "community spirit" and safety. Basolo and Strong (2002) also concluded that physical conditions were important, including cleanliness and traffic. They also found that social relations had a great influence on satisfaction. Other studies (Carp et al., 1976; Franscescato et al., 1987) have also found that physical problems (e.g., poor maintenance, litter, graffiti, noise and pollution) and social relations have a great effect on people's satisfaction with the neighbourhood.

\subsection{Studies of place attachment}

In the research literature on "place attachment" various concepts are used to denominate this phenomenon. It can be defined as "an effective bond between people and places or emotional involvement with places" (Hidalgo \& Hernández, 2001), or "a positive emotional bond that develops between individuals or groups and their environment" (Mesch \& Manor, 1998). Others (Cuba \& Hummon, 1993) use the concept "place identity", which is split into two aspects: display, which is about people leaving their mark on their environment and giving it status and identity, and affiliation, which concerns emotional attachment and sharing values with people in the neighbourhood.

According to Carmen Hidalgo and Bernardo Hernández (2001), people tend to seek out the place where they were born or find a place where they feel comfortable and secure, and that is most often places they are confident with. However, place attachment is not always something that people are very conscious about. People are often unaware of their bonds to the place they live until they must consider leaving their place of residence. Place can have different meanings for different people. Attachment may be related to different spatial ranges such as home, neighbourhood, city or region. Most studies have focused on home and neighbourhood and have proved a high degree of attachment for most people (Hidalgo \& Hernández, 2001). Some studies point at home as the most important place for identity, whereas others consider it only of secondary importance (Cuba \& Hummon, 1993). Two 
studies have looked at the importance of the region. Hidalgo and Hernández (2001) showed that neighbourhood had less importance than home and region. Lee Cuba and David M. Hummon's (1993) study proved that home had the most importance, followed by neighbourhood and region, but there were small differences between the ranges.

Hidalgo and Hernández (2001) showed that attachment to the social environment is more important than attachment to the physical environment. The study by Cuba and Hummon (1993) indicated that nearness to family and friends and other social networks are important, together with the degree of involvement and participation in local organisations. Moreover, identification with the most widespread lifestyle in the neighbourhood had importance. The main finding of the study was that attachment to the neighbourhood was primarily caused by social participation, bonds to friends and other "friend-related" reasons. Regional attachment was connected to the respondents' pattern of activity in the region: the extent to which they used facilities in the region and to some extent to the strength of social networks. Finally, attachment to home was connected to "home-related" explanations. Another study (Mesch \& Manor, 1998) has also showed that home ownership results in stronger place attachment.

\subsection{Summary of characteristics found important in the studies}

Based on this review of various studies regarding housing preferences, place attachment and satisfaction with the home and its surroundings, the following list of important characteristics of housing can be made. Characteristics of home surroundings and location included in various studies include:

- The physical environment: The physical character and appearance of buildings, streets and squares, physical nuisances such as traffic, noise and pollution, maintenance standards in the area, access to green spaces and water;

- The social environment: status and social environment, crime and security, social networks and place attachment, lifestyle;

- Local public and private service facilities: Shops, restaurants, social activities, culture and entertainment, institutions, sports facilities, playgrounds and conditions for children, local social networks and associations, and so on; and

- Location and transport: Distances to jobs, education and urban centres, transportation opportunities, and distances to family and friends.

The importance of each of these elements varies somewhat between the different studies depending on the scope of research, and the location and character of households studied.
It can be concluded from this discussion that specific studies of preference tend to place strong weight on all four dimensions. Studies on residential satisfaction tend to emphasise the physical and social surroundings, whereas research on place attachment points to the social environment as the most important.

\subsection{What is important for differences in preferences}

The literature contains various opinions on why there are differences between housing preferences among different households. The following matters affecting housing preferences are discussed below.

- Differences in family situation and stage of life;

- Income and other resources; and

- Culture and lifestyle.

Differences in family situation and changes in life stages are traditionally seen as the most important factors for housing needs and preferences (Skifter Andersen \& Bonke, 1980; Clark \& Onaka, 1983; Howell \& Freese, 1983; Floor \& Van Kempen, 1997). In particular, the changes when children arrive in or leave the family creates dramatic changes in housing demands, particularly when the family establishes its more permanent home. When families have more children, the need for space, facilities and environment changes dramatically. Later, when children move away from home, space requirements are reduced, but this does not always lead to moves to another home because people find other uses for the space and partly because household mobility decreases dramatically over the years (Rossi, 1955; Skifter Andersen \& Bonke, 1980). This is reflected in an overall sharp decline in moves over the years. Among the elderly, mobility is even lower, although there may be radically changed housing preferences in terms of size, price, tenure, types of building and location.

There are several reasons why the housing career is not always the same for families with the same family career. First, there are differences in working careers and related income development (see below), which means that the economic resources and associated housing options are different. These limitations are more or less reflected in housing preferences depending on how realistically people can assess their future opportunities. Second, there are differences in the opportunities that the housing market offers in different geographical areas. Because of employment, social ties and general place attachment (Hidalgo \& Hernándes 2001; Mulder, 2007), most people are very much bound to a specific geographical area and will often stay there, even if they do not find adequate housing opportunities. Finally, the emergence of a form of "path dependency in housing" (Clapham, 2005) often leads to constraints on the housing market. Peoples' housing aspirations and housing 
choices are likely to depend on their previous accommodation and careers. First, the housing in which one grows up is very important because people tend to choose the same type of housing that they grew up in (Ærø, 2002). It has also been proved that the first housing and location chosen after completing one's education have an enormous impact on later housing careers, and housing in midlife is also crucial for the preferences people have when they become elderly (Howell \& Freese, 1983). In contrast to earlier, however, the family career is no longer so straightforward because of more frequent divorce and career changes. Therefore, expectations for the future are not as static as earlier, which may affect housing preferences if the housing situation is regarded as provisional (Floor \& Van Kempen, 1997).

Individuals' development over their lifecycles in terms of employment and income also has a significant impact on housing preferences, in both the short and the long terms. While people are young, residential location is influenced by the location of educational institutions, whereas later it is more influenced by workplace location. Incomes, and thus housing opportunities, rise at the beginning of one's career until the mid-forties and then fall off sharply after age 60 . However, owner-occupiers simultaneously accumulate housing wealth over time, which means that they can maintain their housing consumption under declining income.

It has been proved that not only current income affects housing choice, but also expected income over one's remaining lifetime (Artle \& Varayia, 1978; Wheaton, 1985). People with higher education, all other things being equal, have greater expectations for future income than those with low education and will therefore also have a greater preferences for larger and more expensive homes in better surroundings. The combination of this and the "path dependency" in housing is especially important for the degree to which families choose to establish themselves in owner-occupied homes. Some households especially those with a high education or higher incomes in early stages of life - buy a home at an early stage and remain in it during the rest of their lives. Others that do not succeed in buying a home in the family's establishment phase may stay in rented accommodation their entire lives, although they would prefer owner-occupancy (Skifter Andersen \& Bonke, 1980).

\subsection{Culture and lifestyle}

Ærø (2002) proposed that "cultural" differences greatly determine the priorities people have when choosing accommodation. He defines three groups:

- Those that do not choose (pre-modern modality). For this group it is a given where you feel at home. The home chooses, so to speak, the occupier and therefore it makes no sense to talk about a choice. One feels at home in one certain place and all others are foreign. Where this is depends on conventions and traditions. One settles where family, ancestors, friends and colleagues have always lived. Housing choice is not reflected, not debatable, and requires no explanation of why one lives where one does.

- Those that choose (modern modality). With this modality, the "right" housing choice is very important, and the question of where to live is much reflected upon. The choice is rationally explained by economic or functional considerations, and is attributable to one's position in society, often provided by a lifelong identity one has obtained through work.

- Those that constantly choose (late-modern modality). In this situation, housing choices are unclear and constantly changing. How does one choose the "right" home when the right choice today may have no value tomorrow? In a world without fixed values, it is difficult and perhaps pointless to choose. Permanent choices mean that something else is rejected, which is unpleasant. Therefore one does not make a choice and feels at home everywhere, but also feels like a stranger everywhere.

This theory suggests that there may be great variation in what significance the properties of the home and its surroundings and location have for people. People in the first group have selected specific locations in advance with a given social, cultural and physical content because they are attached to them. Such persons will either express preferences that correspond to the pre-existing content or will not have any special preferences. Similarly, the third group is not likely to have particularly strong preferences concerning the surroundings of the home, but perhaps more for its location and access to services, transport and culture. For some, the home is just one of several places where they feel at home. They feel about as familiar with places while travelling and vacationing. The home is a place where one relaxes and sleeps, whereas real life is carried out elsewhere. For the second group, the home is very important as the basis of family life. Especially if there are children, the home and its surroundings are of great importance, which is reflected in preferences. This group can be expected to have many and strong preferences. The point here is that lifestyle and degree of place attachment can explain whether people have strong preferences for many aspects simultaneously, or if they only have a few strong preferences.

Another point is that the housing situation that the family has already established may be crucial for preferences because they have adapted to this situation. Some qualities of the local neighbourhood may be self-evident to them because they cannot imagine living anywhere else; this especially holds for the first of the three groups. For example, people that live 
in the countryside may not see nature as something that is particularly important to prioritise because they live in the middle of it, whereas nature and parks may be more important to those that lack it and live in cities. Some may prioritise rectifying deprivation rather than selecting qualities that are obvious to them.

\section{The Danish survey on housing preferences}

This survey was conducted among 2,500 persons over 15 years old. The sample was a statistically random selection from public registers of the Statistical Office of Denmark. Among these, 1,500 telephone interviews were carried out, corresponding to a response rate of $60 \%$. The respondents were compared to the age and sex distribution of the entire Danish population and the minor difference was corrected by weighting the data. Data on the respondents' age, family situation, income, occupation and education were added from public registers. In the survey, "stated preferences" were studied by asking people about their ideal housing preferences. The questionnaire concerned topics such as preferences for tenure, home size, building type, type of location and properties of surroundings and location. In addition, there were questions about the reasons for preferences for renting or owner-occupation.

This article analyses the preferences for properties and qualities of home surroundings and locations. The housing preferences in this study were obtained by asking people what qualities were important for their choice of home. They can be placed into five groups:

a) Physical conditions

- Undisturbed by noise from streets and so on

- Proximity to green areas

- Proximity to the sea or a lake

b) Social conditions in neighbourhood

- Limited social problems

- No problems with crime

- Residents are not too different

- Not too many immigrants

c) Conditions for children

- Proximity to schools and day-care institutions

- Good conditions for children in general

d) Service and facilities

- Communal facilities, community centres and so on

- Proximity to the city's pulse: cafes and cultural life

e) Location and transport facilities

- Access to good public transport

- Proximity to workplace

- Proximity to friends and family

- Proximity to the place where one grew up
Respondents were asked whether these properties had a) high importance, b) some importance or c) no importance. On this basis, an index was calculated. An index of 100 means that all respondents believed that the property was very important, and 0 means that all believed that it had no impact.

\section{Importance of various preferences}

Figure 1 shows average size of the index for the importance of the preferences asked about. On average, proximity to green areas seems to be the most important quality, and many people in Denmark also prioritise nearness to water (the sea or lakes). This may be a special Danish phenomenon because Denmark is a country with a very long coastline. In connection with wishes to live near nature, it is important for many people to avoid places with noise pollution. Social conditions in the neighbourhood are also very important for the choice of neighbourhood. This especially applies to the fear of crime and visible social problems. Denmark is a welfare state with less crime and fewer social problems compared to many other countries, and so it would be expected that these conditions would be more important than elsewhere.

Until recently, Denmark had quite a homogenous population with few immigrants with other cultural backgrounds and relatively small class differences. In recent years, especially after 1990, the country has received refugees and immigrants, now constituting about $5 \%$ of the total population. This has caused some political turmoil and debate with a tendency to depict immigrants very negatively. There has also been some ethnic segregation and concentration of immigrants in certain social housing projects. However, this has generally not resulted in strong preferences among the Danes for avoiding neighbourhoods with many immigrants. As can be seen from Figure 1, the importance of living in a neighbourhood with few immigrants averages somewhere between "not important at all" and "some importance". Taking into account that only a minority of households have children, the conditions for children and proximity to schools and day-care institutions are very important to the Danes. This is discussed in greater detail below. Only a few households prioritise the presence of communal facilities such as community centres in the neighbourhood.

One preference concerns nearness to the life and services provided in major towns and cities. On average, only a minority put special weight on this quality. As shown below, this relates to certain groups, especially young singles and couples without children. Denmark has a good public transport system and access to public transport is important for many respondents, more important than proximity to the workplace. Social networks also have some importance, especially proximity to family and friends. Only a few deem it important to settle near the place where they spent their childhood. 


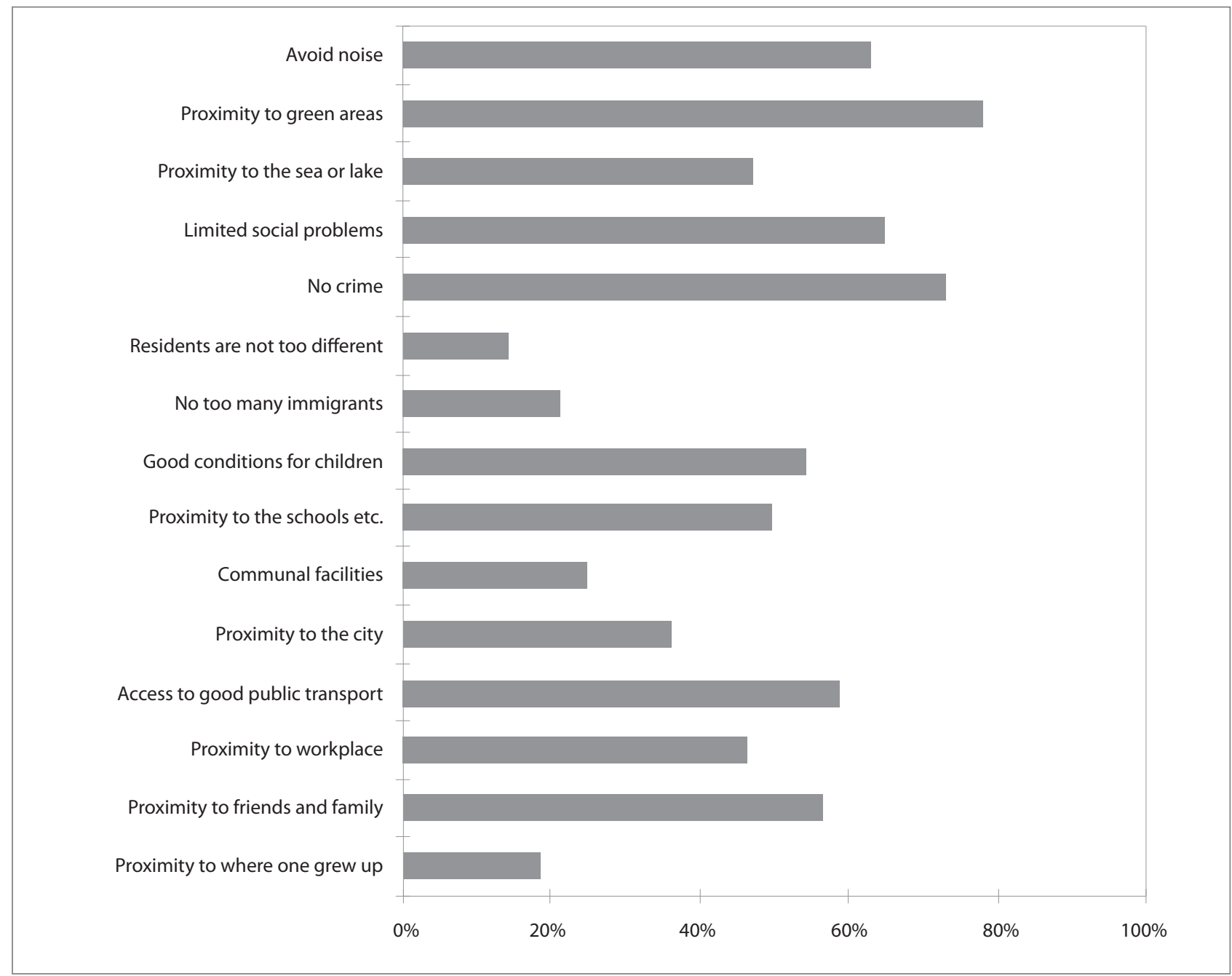

Note: $100=$ very important, $0=$ not important at all.

Figure 1: Average index for strength of preferences for home surroundings and locations.

\section{Coherence between various preferences for surroundings and location}

To obtain a better understanding of what lies behind location and surrounding preferences, the interaction of preferences with one another was analyzed. In addition, factor analysis was used to interpret the underlying motives. The section on earlier studies refers to Ærø’s study (2002), which proposes that lifestyle reasons may cause some people to have strong preferences for many aspects simultaneously, whereas others only have a few. Moreover, the housing situation that the family has already established may be crucial for their preferences because they have adapted to this situation. Some properties of the environment may be obvious to them (perhaps especially to the first of Ærø's three groups) because they cannot imagine living anywhere else.
It is likely that there is a direct correlation between some of the preferences. This especially applies to physical and social conditions and the circumstances of children. However, there is a positive correlation between almost all variables. This suggests that some people responded positively to many issues, whereas others prioritised only a few of them. This confirms Ærø's hypothesis that some families have many priorities and aspirations for home environment and location, whereas others have few priorities. For one of Ærø’s groups (Group 3: those that constantly choose), it is likely that they have a particularly strong priority to stay close to the city's pulse or close to good transport facilities. For another group (those that do not choose because the choice of a certain place is already a given due to family and friends), it is expected that they want to live close to where they grew up. It turns out that these two preferences rarely correlate with the other preferences and that preferences for the city's pulse and access to transport negatively correlate with the desire to live close to where one grew up. Thus, two very different groups have these preferences. 
Concerning preferences for social conditions, there is a very strong link between the desire to avoid social problems and crime (Table 2). The relationship is not quite as strong as with the desire to avoid immigrants and for residents not to be too different. However, there is a relatively strong link between the desire to avoid immigrants and the desire for residents of the area not to be too different.

Generally there is only a weak correlation between preferences concerning the social environment and other preferences. For example, there is a somewhat surprisingly weak link to demands for good conditions for children ( 0.10 and below). The only other factor that correlates much with social preferences is the desire to avoid noise, as shown in Table 2. Thus, this involves some of the same people that want to avoid social problems and noise. As one would expect, there is a strong correlation between desires for proximity to green spaces and proximity to water $(0.39)$. There is also some connection between desires for green space and to avoid noise (0.25), involving people that attach importance to peaceful and rural surroundings. Preferences for good conditions for children are closely connected with the desire for good schools and day-care centres (0.67), but also to some extent with the desire for communal facilities in the neighbourhood (0.19). Preferences for living "close to the city's pulse" have low correlation with nearly all other preferences, and in some cases a negative correlation. Examples include the desire for proximity to green areas, avoiding noise and conditions for children. All the other preferences play a very minor role for those that will live in the central parts of cities. There is greater correlation with location variables such as good transport links (0.21) and distance to job/education (0.17). Finally, there is a reasonably good correlation between the desire to live close to friends and family and the desire to live close to the place where one grew up (0.26). Both of the factors correlate to some extent with the desire to live close to work and education ( 0.19 and 0.14 , respectively), but otherwise they have a different relationship with the other variables. The desire to live close to friends and family has a weak correlation with the desire to avoid social problems and crime (0.11 and 0.14), whereas the desire to live close to the place where one grew up correlates to some extent with the desire to

Table 2: Statistical correlation between preferences for the social environment of the home and for avoiding noise.

\begin{tabular}{lllll}
\hline & $\begin{array}{l}\text { Limited } \\
\text { social } \\
\text { problems }\end{array}$ & $\begin{array}{l}\text { No } \\
\text { crime }\end{array}$ & $\begin{array}{l}\text { Residents not } \\
\text { too different }\end{array}$ & $\begin{array}{l}\text { Few } \\
\text { immi- } \\
\text { grants }\end{array}$ \\
\hline No crime & 0.71 & & & \\
\hline $\begin{array}{l}\text { Residents not } \\
\text { too different }\end{array}$ & 0.19 & 0.15 & & \\
\hline Few immigrants & 0.27 & 0.25 & 0.38 & 0.11 \\
\hline Avoiding noise & 0.37 & 0.34 & 0.11 & \\
\hline
\end{tabular}

avoid immigrants and to live in a place where other residents are not too different (0.11 and 0.13 ).

\section{Factor analysis to construct new variables explaining preferences for home surroundings and locations}

Factor analysis is used to identify underlying variables, or factors, that explain the pattern of correlations within a set of observed variables. Factor analysis is often used in data reduction to identify a small number of factors that explain most of the variance observed in a much larger number of manifest variables. Factor analysis can also be used to generate hypotheses regarding causal mechanisms or to screen variables for subsequent analysis.

As shown by the analyses of correlations between answers in the survey, there is interdependence between some of the various preferences for surroundings and location and not between others. To examine to what extent there is a pattern in these dependencies, a factor analysis was applied to the fifteen variables listed above. In this case, the analysis is used to construct new transverse variables or factors that sum up and explain the patterns behind the original answers.

The factor analysis identified six factors that explain two-thirds of the variance in the stated preferences. Table 3 shows the correlation between each of the six factor variables and each of the input variables representing the answers in the survey. The table can be used to interpret the meaning of the six factor variables. They can be explained as:

- Factor 1: Avoid social nuisance: This factor has a very strong link to the preferences on social issues in housing (social problems and crime) and also to noise.

- Factor 2: Good conditions for having children: The most important variables are good conditions for children, good schools and communal facilities. Proximity to the workplace also has some significance.

- Factor 3: Social homogeneity: Residents in the neighbourhood must not be too different, and are preferably Danes. There is some consistency with the desire to live close to the place where one grew up.

- Factor 4: Close to nature and to peaceful surroundings: Living near green areas and water are dominant, as is (to some extent) avoiding noise.

- Factor 5: Close to social networks: Most important is to stay close to the place where one grew up and/or close to friends and family. Proximity to the workplace is also important.

- Factor 6: Close to city life and transport: It is important to stay close to the city's pulse and good public transport links. Here communal facilities in the neighbourhood 
also have a certain weight, as well as proximity to one's job.

The analysis thus suggests that the preferences for home surroundings and locations can be divided into these six dimensions. The first dimension "Avoid social nuisance" is the most important (as was shown in Figure 1) because avoiding social problems and crime are very important preferences. The factor also relates to some extent to the wish not to settle in neighbourhoods with many immigrants. People dominated by this factor may be expected to be very concerned with the status of their neighbourhood (where social problems, crime and immigrants certainly will result in a bad image and low status) or to be people that fear their surroundings to some extent and have a great need of protection (Skifter Andersen, 2008). This is confirmed by the importance for this group of avoiding noise.

As suggested by the analyses of correlation between the preference variables, the demand for social homogeneity in the neighbourhood is a special dimension separated from the factor concerning social nuisances and so on, even if there are weak correlations with social problems and crime. This is interesting: if the fear of living together with foreigners does not concern concrete social problems and crime, what then is the reason? Could it have something to do with the fact that there is a correlation with the preference for living near the place one grew up? This is discussed further below, when looking at the connection between this factor and the preferences for living in the city or living in the countryside.
The fourth factor, Close to nature and to peaceful surroundings, also consists of preferences that are important for many (proximity to green areas and water). This is connected to some extent with the wish for quiet and peaceful surroundings. This factor has a negative correlation with the wish to live near city life, but not as much as could be expected. Most of these people thus do not prioritise city life, but some of them do. For some people that prefer to live in cities, closeness to parks could be very important. It can also be seen that this factor has a greater negative relationship to preferences for living close to the workplace. This can be interpreted as people dominated by this factor either not working (as can be seen below) or being willing to commute in exchange for living closer to natural surroundings. Finally, to some small extent this factor is related to the wish for social networks and communal facilitates. It could be because of this that some people relate their preference for living in the countryside to a wish to join a close-knit local community in these places (Skifter Andersen, in press). There is also a weak correlation between preferences for good conditions for children and for proximity to green spaces, to avoid noise and to live in places where the residents are not too different. All of this could also be for the sake of the children. On the other hand, there is a negative correlation with preferences for city life.

In explaining the last two factors, Ærø's distinction (2002) between pre-modern, modern and late-modern modalities can be applied. The factor Close to social networks could be associated with a pre-modern modality, whereas the factor Close to city life could be related to a late-modern modality. The factor

Table 3: Results of factor analysis of stated preferences (correlation between factors and input variables).

\begin{tabular}{|c|c|c|c|c|c|c|}
\hline \multirow{2}{*}{ Preferences } & \multicolumn{6}{|c|}{ New factors } \\
\hline & 1 & 2 & 3 & 4 & 5 & 6 \\
\hline Avoid noise & 0.61 & 0.13 & -0.02 & 0.24 & -0.07 & -0.07 \\
\hline Limited social problems & 0.87 & 0.02 & 0.18 & 0.06 & 0.08 & -0.01 \\
\hline No crime & 0.86 & 0.02 & 0.14 & 0.03 & 0.07 & 0.09 \\
\hline Proximity to schools and day-care institutions & 0.10 & 0.87 & 0.01 & -0.02 & 0.11 & 0.01 \\
\hline Good conditions for children in general & 0.07 & 0.88 & 0.02 & 0.06 & 0.05 & 0.00 \\
\hline Communal facilities, community centres, etc. & -0.06 & 0.34 & 0.14 & 0.18 & -0.08 & 0.43 \\
\hline Residents are not too different & 0.05 & 0.10 & 0.83 & 0.05 & 0.02 & 0.03 \\
\hline Not too many immigrants & 0.22 & -0.05 & 0.75 & 0.04 & 0.07 & 0.07 \\
\hline Proximity to green areas & 0.21 & 0.15 & 0.04 & 0.78 & 0.01 & 0.03 \\
\hline Proximity to the sea or a lake & 0.08 & -0.07 & 0.05 & 0.81 & 0.08 & 0.06 \\
\hline Access to good public transport & 0.07 & 0.04 & -0.08 & 0.05 & 0.12 & 0.70 \\
\hline Proximity to the city's pulse: cafes and cultural life & -0.04 & -0.11 & 0.13 & -0.04 & 0.04 & 0.72 \\
\hline Proximity to workplace & 0.08 & 0.22 & -0.15 & -0.17 & 0.52 & 0.27 \\
\hline Proximity to friends and family & 0.08 & -0.04 & 0.01 & 0.11 & 0.73 & 0.18 \\
\hline Proximity to the place where one grew up & -0.09 & 0.08 & 0.23 & 0.09 & 0.73 & -0.22 \\
\hline Explained part of variance in input variables (\%) & 18.3 & 11.5 & 9.7 & 8.1 & 7.7 & 7.5 \\
\hline Eigenvalues & 2.74 & 1.72 & 1.45 & 1.22 & 1.15 & 1.12 \\
\hline
\end{tabular}

Note: The analysis is Varimax rotated. 
Close to social network is strongly related to preferences for living near the place where one grew up and near family and friends. It is not related to any of the other preferences except for preferences for proximity to the workplace. It is appropriate to consider people controlled by this factor as not making a choice except for living a certain place - most often the place where they grew up. The factor Close to city life has a strong correlation with preferences for city life, for access to public transport and for communal facilities. Moreover, proximity to work is important. It negatively correlates with the wish to live where one grew up, but family and friends (and perhaps especially the latter) have some importance. All the other kinds of preferences are not important for this factor. It could easily be associated with a group of people in the late-modern modality for whom access to city life and transport are the dominating motives, whereas many other kinds of preferences are not important.

\section{Connection between preferred degree of urbanisation and preference factors}

As might be expected, there is a strong relation between stated preferences for surroundings and whether people prefer to live in cities or in the countryside. Table 4 shows the average factor scores (multiplied by 100) for respondents divided based on their stated preference for living in cities, towns, villages or the countryside. The score varies from -100 to 100 (usually from -1 to 1 ).

The last column of Table 4 shows the distribution of respondents by their preferred location. Just under half of them prefer to live in major towns and cities, in suburbs or close to the centre. One out of four prefer small or medium-sized towns, $13 \%$ would like to live in a village and $15 \%$ in the countryside. Compared to the place they live, somewhat more people want to live in the countryside than their present home. Fewer people want to live in dense areas near city centres than are actually living there. As expected, those preferring to live in city centres are also strongly influenced by the factor "Close to city life", and this influence drops sharply with less urbanisation. However, it also has some importance in the suburbs. As might be expected, preferences for closeness to nature have the opposite connection with preferences for degree of urbanisation. This is very strong for people that prefer to live in villages and the countryside, and very weak in the city.

This connection also exists to some extent for the factor "social networks". It is stronger in suburbs, towns and villages, but weak for people that want to live in city centres. Somewhat surprisingly, it is also weaker in connection with preferences for living in the countryside. One explanation for this could be that living in the countryside is connected to some social isolation because there is a greater distance to neighbours. The remaining three factors have more inconsistent variation with the preferred degree of urbanisation. Concerns with social problems are most important in the suburbs and in urban areas near city centres (perhaps because many problems have been located here in the last 30 years), and to some extent in provincial towns. It is least important in city centres and, after this, in villages. In the first case, the reason could be that people that prefer to live in central cities are more cosmopolitan and more tolerant of social problems and not so frightened by the prospect of crime. It also has something to do with the age of this group, as discussed below. For the countryside, the explanation could be that social problems are not as visible there.

The priority for good conditions for children is strong in dense city areas close to centres. It is more significant because there are far fewer families with children in these areas, whereas there are many in the suburbs. This could be because conditions for children have the greatest importance in places where they are worst. Preferences for good conditions for children are also strong in the villages. They have the least importance in rural areas, where conditions must be considered as excellent except for the long distance to schools and other institutions.

Table 4: Average factor scores (multiplied by 100) for people with different preferences for home location.

\begin{tabular}{|c|c|c|c|c|c|c|c|}
\hline Preferred location & $\begin{array}{l}\text { Avoid } \\
\text { social } \\
\text { nuisance }\end{array}$ & $\begin{array}{l}\text { Conditions } \\
\text { for children }\end{array}$ & $\begin{array}{l}\text { Social } \\
\text { homogeneity }\end{array}$ & $\begin{array}{l}\text { Close } \\
\text { to nature }\end{array}$ & $\begin{array}{l}\text { Social } \\
\text { networks }\end{array}$ & $\begin{array}{l}\text { Close to } \\
\text { city life }\end{array}$ & $\begin{array}{l}\text { Distribution } \\
\text { by preferred } \\
\text { locality (\%) }\end{array}$ \\
\hline Centre of major town/city & -29.3 & -19.9 & 3.4 & -28.1 & -6.4 & 60.4 & 17.0 \\
\hline Dense areas near city centres & 10.6 & 15.4 & -25.8 & -22.9 & -13.1 & 42.5 & 5.0 \\
\hline Suburbs & 11.4 & 5.4 & 5.7 & -2.6 & 5.3 & 12.9 & 26.0 \\
\hline Small or medium-sized towns & 6.7 & 2.3 & 2.2 & -2.6 & 5.2 & -11.9 & 24.0 \\
\hline Village & -3.4 & 14.2 & -0.8 & 24.2 & 4.7 & -42.5 & 13.0 \\
\hline Countryside & 1.2 & -9.7 & -8.7 & 25.1 & -11.2 & -45.7 & 15.0 \\
\hline All & & & & & & & 100.0 \\
\hline
\end{tabular}


Preferences for social homogeneity are significantly lowest in urban areas near city centres. The reason for this could be that these areas are often very mixed. People that live near or are familiar with these areas are used to a heterogeneous population. This is not always the case in the suburbs, which are more divided into various neighbourhoods populated by various social classes and ethnic groups. It is somewhat surprising that people preferring city centres also have a somewhat higher preference for social homogeneity. Perhaps this is a result of the increasing gentrification of the city centres, where more affluent groups are moving into the city. In the countryside social homogeneity is not an issue because people most often live far away from neighbours.

\section{Connection between lifecycle stages and preferences}

To start with, some statistical regression analyses were carried out to establish the connection between background variables on the households and their residential preferences. The analyses yielded poor results. It was difficult to establish models that could explain the variation in preferences. Variables such as income and education were not significant. The most significant variables were those that can be connected to families' lifecycles. One possible explanation is that the connection between the available background variables and preferences is disturbed by the evidence: some people have many strong preferences whereas others have few, and this variation runs across variables such as income and education.

As already discussed in the section on earlier studies of housing preferences, it is to be expected that preferences change over one's lifetime. This is examined in this section using the factor variables determined in the factor analysis. At the same time, examining how these factors vary between lifecycle groups can contribute to further understanding of the meaning of these

Table 5: Respondents in the survey distributed on lifecycle groups.

\begin{tabular}{lll}
\hline Lifecycle group & $\begin{array}{l}\text { Number of } \\
\text { respondents }\end{array}$ & Distribution (\%) \\
\hline Living in parents' home & 137 & 9.0 \\
\hline Young single $<30$ & 28 & 1.8 \\
\hline Young couples $<30$ & 50 & 3.3 \\
\hline Couples with children & 454 & 29.7 \\
\hline Single parents & 46 & 3.0 \\
\hline Singles 30-59 & 79 & 5.2 \\
\hline Couples 30-59 & 210 & 13.7 \\
\hline Elderly couples $60+$ & 309 & 20.2 \\
\hline Elderly singles $60+$ & 108 & 7.1 \\
\hline Mixed households & 107 & 7.0 \\
\hline Total & 1,528 & 100 \\
\hline
\end{tabular}

factors. Respondents were divided into nine lifecycle groups, as shown in Table 5. This division is based on data from public registers on age and family situation. In $7 \%$ of the cases, the respondents were living in a mixed household in which several persons were living together without being a family. These were mostly young people. Nine per cent of respondents were young people still living in their parents' home.

Regarding the meaning of the factors revealed, in Table 6 the factor "social homogeneity" mostly appears among the elderly and especially among singles. An analysis of the specific responses to the questions in the survey reveals that the elderly especially often state a preference to avoid neighbourhoods with many immigrants. This could confirm the assumption that people without a more cosmopolitan view of the world, like many of the elderly, are more inclined to be controlled by this factor in their choice of housing. It could be supported by the fact that the group least dominated by the factor is middle-aged singles and single parents. However, it is not obvious why young singles have a (small) positive factor score. It is even harder to explain why the same group has the most outstanding negative score on the factor "avoid social nuisances".

It is also a bit surprising that the factor "social networks" has more importance for young people than for the elderly. Two explanations can be offered. First, young people that left their birthplace for education in a distant city may place a very high priority on going back to the place where they grew up. For the elderly, who have lived there all of their lives, this is taken for granted. Second, young people with a weak network of friends and without their own family place much weight on living close to their friends, whereas the social network for the elderly is more taken for granted or perhaps absent. It is nevertheless surprising that the social network factor has such a low priority among the elderly. $30 \%$ of the respondents over 60 stated that proximity to family and friends is not important to them.

Table 6 offers an illustration of how preferences for home surroundings and locations change over one's lifetime. It must be remembered, however, that the data reveal the preferences of a cross-section of the population, and that there could be differences between different generations. From Table 6, the following observations can be made about preference developments during the lifecycle. For young people living at home, it is very important to live close to city life when they try to get their own home. They also place a lot of weight on closeness to social networks. It is important for them to live close to friends and perhaps also near their family. Some still feel like children and place weight on good conditions for children; that is, sports facilities, youth clubs, and so on. Proximity to nature has no priority. When leaving home and living as young singles, preferences for city life are even more pronounced. 
Table 6: Average scores (multiplied by 100) for factors explaining preferences for home surroundings and locations at different life stages.

\begin{tabular}{lcccccc}
\hline Lifecycle group & $\begin{array}{l}\text { Avoid social } \\
\text { nuisance }\end{array}$ & $\begin{array}{l}\text { Conditions } \\
\text { for children }\end{array}$ & $\begin{array}{l}\text { Social } \\
\text { homogeneity }\end{array}$ & $\begin{array}{l}\text { Close } \\
\text { to nature }\end{array}$ & $\begin{array}{l}\text { Social } \\
\text { networks }\end{array}$ & $\begin{array}{l}\text { Close to } \\
\text { city life }\end{array}$ \\
\hline Living in parents' home & -8 & 22 & -6 & -57 & 36 & 44 \\
\hline Young single $<30$ & -54 & -52 & 13 & -98 & 12 & 46 \\
\hline Young couples $<30$ & -4 & -3 & -9 & -27 & 20 & 14 \\
\hline Couples with children & 12 & 59 & -8 & -2 & 6 & -19 \\
\hline Single parents & 7 & 50 & -15 & -16 & -17 & -1 \\
\hline Singles 30-59 & -4 & -37 & -34 & 1 & -13 & 19 \\
\hline Couples 30-59 & 7 & -25 & 2 & 8 & -12 & -12 \\
\hline Elderly couples 60+ & -10 & -45 & 13 & 34 & -15 & -6 \\
\hline Elderly singles 60+ & 5 & -86 & 42 & 28 & -22 & 18 \\
\hline Mixed households & -15 & -24 & -2 & -1 & 12 & 13
\end{tabular}

Social nuisances, conditions for children and nature play no role at all. Social networks are still important but not as much as when they lived at home. Middle-aged singles (30-59 years) still have preferences for city life, but not as pronounced as those of the young. They differ from young singles by having very low preferences for social homogeneity in their neighbourhood and also for social networks. Perhaps this can be partly explained by the difference between generations, in which public concern about neighbourhoods with many immigrants and social problems has been more noticeable in the last 20 years.

When young people move together and create the beginning of a family, preferences begin to change. Closeness to city life is still important, but not so much as for young singles. Closeness to social networks acquires greater importance and social nuisances and conditions for children are no longer very unimportant. For middle-aged couples (30-59 years) without children, preferences are somewhat different. This group may be dominated by people that have either given up on having children or that already had them earlier. Most of them do not want to live close to city life; they are not concerned with conditions for children and social networks, but some of them have preferences for nature, social homogeneity and avoiding social problems. However, the most dramatic change in preferences occurs when people have children. Conditions for children become the single most important preference and closeness to city life the most unimportant. There is also a higher preference for avoiding social nuisances, which also can be explained as consideration for children. Social networks still have a little importance. Single parents do not deviate very much from couples with children.

Finally, preferences change dramatically among elderly couples and singles over 60 . Closeness to nature and social homogeneity become the dominating and central preferences. There are some differences between singles and couples, which to some extent can be explained by the fact that singles are older on average. Some singles want to live close to city life, whereas couples do not. Singles are also much more concerned with social homogeneity and to a small extent with social problems. They also have preferences for nature, but are somewhat less concerned with this than couples. It is a bit surprising that singles also have less preference for social networks because one would expect this to have greater importance for people living alone.

\section{Conclusion}

This article answered the following questions:

- What qualities of home surroundings and locations are most important?

- How can variation in the preferences for these qualities be explained?

- How do preferences develop with different stages in the lifecycle?

- What are the differences among people with different preferences for living in cities or the countryside?

The housing preferences in this study were obtained by asking a random selection of people in Denmark over 15 about what qualities of home surroundings and locations have the most importance for their choice of home. There are two reasons why housing preferences are difficult to ascertain and why the results of these kinds of studies must be treated with caution. First, stated preferences sometimes do and sometimes do not take into account the extent to which it is possible to realise them. People with the same underlying preferences could give different answers because they differ in considering how realistic they are. Second, the way people set priorities in relation to their future choice of a home can be influenced by their present housing situation and especially by present disadvantages, which they very much want to improve. For instance, people living in cities that lack green spaces could therefore have a greater preference for green spaces than people living 
in the countryside, where there is plenty of nature. Preferences must be related to the present housing situation and the circumstances in which people see their future living place. Some preferences for home locations and surroundings are taken for granted and are not discussed.

An analysis of earlier research on preferences for surroundings, housing satisfaction and place attachment showed that the characteristics of home surroundings and locations that people pay attention to can be divided into four dimensions: a) the physical environment, b) the social environment, c) access to local public and private service facilities and $\mathrm{d}$ ) location and transport in a broader context. A factor analysis of the 16 different questions about preferences in the Danish survey can be interpreted such that six different factors have influence on how people choose their home locations and surroundings. They are named: a) avoid social nuisance, b) good conditions for having children, c) social homogeneity, d) proximity to nature and peaceful surroundings, e) close to social networks and f) close to city life and transport. The social environment has thus been split up into three dimensions: social nuisances, social homogeneity and spatial proximity to one's social network. It is an interesting result that preferences for avoiding neighbourhoods with social problems and crime are not very connected to preferences for social homogeneity; that is, living in a neighbourhood with few ethnic minorities and where residents are not too different. It is thus not the same people that have these different priorities even if social problems and crime in neighbourhoods have often been connected with multiethnic neighbourhoods in the Danish media. This could mean that preferences for social homogeneity in the neighbourhood have more to do with political opinions and perhaps status.

The study indicates that, for the Danish population as a whole, most people place weight on avoiding social nuisances, on proximity to nature and so on, and on proximity to family and friends. However, preferences vary greatly between different subgroups of the population. This article uses Ærø’s (2002) housing choice theory, which defines three groups:

- Those that do not choose: (a pre-modern modality)

- Those that choose: (a modern modality)

- Those that constantly choose (a late-modern modality)

Persons in the first group have selected specific locations in advance with a given social, cultural and physical content because they are attached to them. Such persons will either express preferences that correspond to the pre-existing content, or will not have any special preferences. In addition, the third group is not likely to have particularly strong preferences concerning the home and its surroundings, but more for its location and access to services, transport and culture. These are people for whom the home is just one of several places where they feel at home. They feel equally familiar with places while travelling and on vacation. The home is a place where they relax and sleep, whereas real life is experienced elsewhere. For the second group, the home is very important as the basis of family life, and thus serves to make daily life convenient and functional. Especially if there are children, the home and its surroundings are of great importance, which is reflected in the preferences. This group has many and strong preferences.

The empirical evidence in this article supports Ærø’s theory. First, it was shown that some of the respondents had strong preferences for many different qualities of the home surroundings and location, whereas others had very few. It was shown that preferences that could be connected to the first group, the factor called close to social networks (living close to family and friends and to the place where one grew up), had little correlation with other preferences, meaning that people with these preferences seldom have other preferences. It was also shown that people that have preferences that could be connected to the last group (living close to city life and to transport facilities) seldom have other preferences. Most of the other preferences, however, often appeared together, indicating that the second group had many different preferences.

This study illustrates how preferences for home surroundings and locations change over one's lifetime, as expected. For young people, the dominating factor is closeness to city life and transport; this preference gradually falls with age and when they form couples. These preferences totally disappear when people have children. Proximity to social networks is also very important for young people and not so important for families with children and the elderly, which is somewhat surprising. The opposite changes take place for preferences for nature, which are very low among young people and very high among the elderly. Preferences for good conditions for children are (as might be expected) very important for families with children and also for some young couples expecting children. It is also most important for families with children to avoid social nuisances in the neighbourhood, whereas this has no importance for young singles. Preferences for social homogeneity in the neighbourhood are very important for elderly single people over 60 and to some extent for elderly couples.

There are some very expected connections between location preferences for living in a city, a provincial town or the countryside and preferences concerning home surroundings and locations, but there are also some unexpected ones. As expected, preferences for city life are much more frequent in cities than in villages and the countryside, and proximity to nature is the other way around. Perhaps more unexpected is the fact that social networks are most important in suburbs, provincial towns and villages, but not in the countryside. Preferences for avoiding social nuisances are most common in dense areas in cities outside city centres and in the suburbs, which could be 
explained by the fact that it is there that social problems and crime are most commonly found. Emphasis on social homogeneity is most often connected to preferences for suburbs.

\section{Hans Skifter Andersen}

Danish Building Research Institute at the University of Aalborg, Hørsholm, Denmark

E-mail: hsa@sbi.dk

\section{References}

Ærø, T. (2002) Boligpræferencer, boligvalg \& livsstil. Doctoral thesis. Hørsholm, Statens Byggeforskningsinstitut, Department of Housing and Urban Research.

Erø, T. (2006) Residential choice from a lifestyle perspective. Housing, Theory and Society, 23(2), pp. 109-130. DOI: $10.1080 / 14036090600773139$

Artle, R. \& Varaiya, P. (1978) Life cycle consumption and homeownership. Journal of Economic Theory, 18(1), pp. 38-58. DOI: 10.1016/0022-0531(78)90041-8

Basolo, V. \& Strong, D. (2002) Understanding the neighbourhood: From residents' perception and needs to action. Housing Policy Debate, 13(1), pp. 83-105.

Carp, F., Zawadski, R. \& Shokron, H. (1976) Dimensions of urban environmental quality. Environment and Behaviour, 8(2), pp. 239-265. DOI: $10.1177 / 001391657682004$

Clapham, D. (2005) The meaning of housing: A pathways approach. Bristol, Policy Press.

Clark, W. A. V. \& Onaka, J. L. (1983) Life cycle and housing adjustment as explanations of residential mobility. Urban Studies, 20(1), pp. 47-57.

Coolen, H. \& Hoekstra, J. (2001) Values as determinants of preferences for housing attributes. Journal of Housing and the Built Environment, 16(3-4), pp. 285-306. DOI: 10.1023/A:1012587323814

Costa Pinho, T. (2000) Residential contexts of social exclusion: Images and identities. Paper presented at the International Research conference of the Institute for Housing Research, Uppsala University, under the auspices of the European Network for Housing Research, 26-30 June, Gävle, Sweden. Typescript.

Cuba, L. \& Hummon, D. M. (1993) A place to call home: Identification with dwelling, community and region. The Sociological Quarterly, 34(1), pp. 111-131. DOI: 10.1111/j.1533-8525.1993.tb00133.x

Floor, H. \& Van Kempen, R. (1997) Analysing housing preferences with decision plan nets. Scandinavian Housing and Planning Research, 14(1), pp. 27-42.

Franscescato, G., Wiedemann, S. \& Anderson, J. R. (1987) Residential satisfaction. In: Van Vliet, W. et al. (eds.) Housing and neighbourhoods: Theoretical and empirical contributions, pp. 43-58. New York, Greenwood Press.

Galster, G., Hayes, C. \& Johnston, J. (2002) Identifying robust, parsimonious indicators of neighbourhood quality of life. Journal of Planning Education and Research, 24(3), pp. 265-280. DOI: $10.1177 / 0739456 \times 04267717$

Gruber, K. J. \& Shelton, G. G. (1986) Assessment of neighbourhood satisfaction by residents of three housing types. Social Indicators Research, 19(3), pp. 303-315. DOI: 10.1007/BF00300363

Hidalgo, M. C. \& Hernández, B. (2001) Place attachment: Conceptual and empirical questions. Journal of Environmental Psychology, 21(3), pp. 273-281. DOI: 10.1006/jevp.2001.0221

Howell, F. M. \& Freese, W. (1983) Size of place, residential preferences and the life cycle: How people come to like where they live. American Sociological Review, 48(4), pp. 569-580. DOI: $10.2307 / 2117723$

Johnston, R. J. (1973) Spatial patterns in suburban evaluations. Environment and Planning A, 5(3), pp. 385-395. DOI: 10.1068/a050385

Kauko, T. (2006). What makes a location attractive for the housing consumer? Preliminary findings from metropolitan Helsinki and Randstad Holland using the analytical hierarchy process. Journal of Housing and the Built Environment, 21(2), 159-176. DOI: 10.1007/ s10901-006-9040-y

Mesch, G. S. \& Manor, O. (1998) Social ties, environmental perception and local attachment. Environment and Behaviour, 30(4), pp. 504-519. DOI: 10.1177/001391659803000405

Molin, E. J. E., Oppewal, H. \& Timmermanns, H. J. P. (2001) Analysing heterogeneity in conjoint estimates of residential preferences. Journal of Housing and the Built Environment, 16(3-4), pp. 267-284. DOI: 10.1023/A:1012539415696

Mulder, C. H. (2007) The family context and residential choice: A challenge for new research. Population, Space and Place, 13(4), pp. 265-278. DOI: 10.1002/psp.456

Parkes, A., Kearns, A. \& Atkinson, R. (2002) What makes people dissatisfied with their neighbourhoods? Urban Studies, 39(13), pp. 2413-2438. DOI: 10.1080/0042098022000027031

Rossi P. H. (1955) Why families move. Glencoe, IL, Free Press.

Sirgy, M. J., Grzeeskowial, S. \& Su, C. (2005) Explaining housing preferences and choice: The role of self-congruity and functional congruity. Journal of Housing and the Built Environment, 20(4), pp. 329-347. DOI: 10.1007/s10901-005-9020-7

Skifter Andersen, H. (2008) Why do residents want to leave deprived neighbourhoods? The importance of residents' subjective evaluations of their neighbourhood and its reputation. Journal of Housing and the Built Environment, 23(2), pp. 79-101. DOI: 10.1007/ s10901-008-9109-x

Skifter Andersen, H. (in press) Explanations for long-distance counter-urban migration into fringe areas in Denmark. Population, Space and Place.

Skifter Andersen, H. \& Bonke, J. (1980) Boligsektorens fordelingsmæssige virkninger. Copehagen, Lavindkomstkommisionen.

Timmermans, H., Molin, E. \& Van Noortvijk, L. (1994) Housing choice processes: Stated versus revealed modelling approaches. Journal of Housing and the Built Environment, 9(3), pp. 215-227. DOI: 10.1007/BF02496997

Vorel, J. \& Maier, K. (2007) Learning the public preferences for living environment characteristics: the experimental approach. Paper presented at REAL CORP 007, 20-23 May, Vienna, Austria. Typescript.

Wheaton, W. C. (1985) Life-cycle theory, inflation, and the demand for housing. Journal of Urban Economics 18(2), pp. 161-179. DOI: 10.1016/0094-1190(85)90014-2 